\title{
Intermittent Fasting Modulation of the Diabetic Syndrome in Streptozoto- cin-Injected Rats: Post-Mortem Investigations
}

\author{
Louiza Belkacemi ${ }^{1}$, Ghalem Selselet-Attou ${ }^{1}$, Marie-Hélène Antoine ${ }^{2}$, Joelle Nortier ${ }^{2}$, \\ Emeline Hupkens ${ }^{2}$, Abdullah Sener ${ }^{2}$ and Willy J. Malaisse ${ }^{2, *}$ \\ ${ }^{1}$ Laboratoire de Technologie Alimentaire et Nutrition, Université de Mostaganem, Mostaganem, Algeria; ${ }^{2}$ Laboratory of \\ Experimental Hormonology, Université Libre de Bruxelles, Brussels, Belgium
}

\begin{abstract}
Intermittent fasting was previously reported to exert beneficial effects in sand rats, an animal model of diabetes. The present report complements recent comparable findings recorded in streptozotocin-induced diabetic rats (STZ rats). Intermittent fasting minimized the increase in pancreatic, hepatic and renal weight otherwise observed in the STZ rats. The glycogen content of the liver was higher in the STZ rats than in the control animals. It was positively correlated, at the individual level, with the hepatic glucose content. Significant positive correlations also prevailed between the plasma glucose concentration at sacrifice, which was lower in intermittently fasting or calorie-restricted STZ rats than in nonfasting STZ rats, and either the liver glucose content or liver total carbohydrate content. The kidney PCNA (proliferating cell nuclear antigen) index, as well as the plasma creatinine and urea concentrations, were also lower in intermittently fasting or calorie-restricted STZ rats than in non-fasting diabetic animals. These findings reinforce the view that intermittent fasting may exert a favourable effect, in terms of glucose homeostasis and the undesirable consequences of its perturbation, in diabetic animals.
\end{abstract}

Keywords: Streptozotocin-induced diabetic rats, kidney proliferating cell nuclear antigen, liver histology, intermittent fasting, caloric restriction.

\section{INTRODUCTION}

In a previous report from our group, attention was drawn to the beneficial effects of intermittent fasting on glucose tolerance, insulin sensitivity, individual $\beta$-cell and islet area and percentage of apoptotic $\beta$-cells in the pancreas of streptozotocin-induced diabetic rats exposed for 30 days to intermittent fasting from 5 p.m. to 8 a.m. [1]. The present report provides complementary information on pancreatic, liver and kidney weight, liver histology and glycogen content, kidney PCNA (proliferating cell nuclear antigen) index, and plasma creatinine and urea concentrations, in both control and STZ rats either given for 30 days before sacrifice free access to food, deprived daily of food from 5 p.m. to 8 a.m., or given access from 5 p.m. onwards to an amount of food comparable to that ingested by the intermittently fasting animals.

\section{MATERIALS AND METHODS}

The experimental design and animals used in the present study were the same as those described in detail in a recent publication [1]. Briefly, 8-10 weeks after birth, female Wistar rats were injected intraperitoneally, after overnight starvation, with streptozotocin (STZ, $65 \mathrm{mg} / \mathrm{kg}$ body wt.) or its citrate buffer vehicle (control rats). Twenty days later and for the ensuing 30 days, the control and STZ rats were either given free access to food (NF: non-fasting), deprived of food

*Address correspondence to this author at the Laboratory of Experimental Hormonology, Université Libre de Bruxelles, 808 Route de Lennik, B-1070 Brussels, Belgium; Tel: 32-2-5556237; Fax: 32-2-5556356;

E-mail:malaisse@ulb.ac.be

1874-3609/13 from 5 p.m. to 8 a.m. (IF: intermittently fasting) or given access from 5 p.m. onwards to an amount of food comparable to that ingested by the IF rats (CR: calorie-restricted rats).

For the histological study of the liver, hepatic samples were fixed in a $10 \%(\mathrm{w} / \mathrm{v})$ formaldehyde solution and embedded in paraffin. Sections $(5 \mu \mathrm{m})$ were deparaffined and rehydrated for periodic acid Schiff (PAS) staining. The liver slides were examined under light microscopy.

The glycogen content of the liver was measured by the $\alpha$ amyloglucosidase procedure. After extraction of the hepatic samples [2], aliquots parts $(0.5 \mathrm{ml})$ of the extracts were incubated for $60 \mathrm{~min}$ at $55^{\circ} \mathrm{C}$ after mixing with $1.2 \mathrm{ml}$ of an acetate buffer $(0.05 \mathrm{M}, \mathrm{pH} 5.0)$ and, when required, $0.3 \mathrm{ml}$ of a solution of $\alpha$-amyloglucosidase prepared in the same acetate buffer. The samples were than heated for $10 \mathrm{~min}$ at $70^{\circ} \mathrm{C}$, centrifuged for $2 \mathrm{~min}$ at $1,000 \mathrm{~g}$, and eventually examined for their D-glucose content. Standard amounts of glycogen $(125,250$ and $500 \mu \mathrm{g}$ per sample) were treated in the same manner.

For the histological study of the kidney, the renal sections were stained with Schiff periodic acid.

For measuring the kidney PCNA index, kidney sections (4 $\mu \mathrm{m})$ were deparaffinized with xylene, incubated in isopropanol for $5 \mathrm{~min}$ and then in methanol containing 3\% $\mathrm{H}_{2} \mathrm{O}_{2}$ for $30 \mathrm{~min}$. This was followed by rinses with PBS and an incubation in 5\% normal goat serum (Abcam ab7481; Cambridge, UK) in PBS for $1 \mathrm{~h}$. Incubation with the primary antibodies rabbit polyclonal anti PCNA (Abcam ab2426; 
Cambridge, UK) was performed overnight at $4^{\circ} \mathrm{C}$. Control sections were incubated with normal goat serum instead of the primary antibody. Detection of tubular $\mathrm{PCNA}^{+}$cells was performed with an avidin-biotin based peroxydase detection kit (Vector, PK 6101, Peterborough, UK) using 3,3'diaminobenzidine as the chromogen. The PCNA expression defined as nuclear staining was counted in 20 fields by two independent observers blinded to the treatment using light microscopy at a magnification of $400 \mathrm{x}$ and expressed as an average of $\mathrm{PCNA}^{+}$cells per field. The PCNA index represents the number of PCNA positive cells relative to the total number of cells. Such a total number of cells averaged $200 \pm$ $4(n=197)$, with extreme values of 101 and 395 .

At sacrifice, Jaffe-based creatinine measurements [3] were made in COBAS C111 automated Analyzer (Roche Diagnostics, Indianapolis, IN, USA). Urea was measured with urease and glutamate dehydrogenase methods [4] using the COBAS C111 automated Analyzer. The reagents of the kinetic Jaffe reaction and urea measurements were provided by the same manufacturers.

All results are presented as mean values ( \pm SEM) together with the number of individual observations (n). The statistical significance of differences between mean values was assessed by use of Student's t-test.

\section{RESULTS}

\section{Organ Weight}

Table 1 provides information on the wet weight of the pancreas, liver and both right and left kidney in the six groups of rats considered in the present study. Expressed relative to body weight, the pancreatic gland weight was higher $(p<0.005)$ in the STZ rats than in the control animals. In both control and STZ rats, the pancreatic weight, expressed relative to the mean value found in NF animals, was lower in IF rats than in CR rats, such a difference achieving statistical significance for both the absolute values (g) of pancreatic weight $(86.2 \pm 3.4 \% ; \mathrm{n}=6$ in IF rats versus $113.6 \pm 8.3 \% ; \mathrm{n}=7$ in $\mathrm{CR}$ rats; $\mathrm{p}<0.02$ ) and their relative value ( $\%$ of body wt.) of pancreatic weight $(90.2 \pm 6.0 \%$ in IF rats versus $112.7 \pm 7.6 \% ; n=7$ in CR rats; $\mathrm{p}<0.05)$.

Whether expressed in absolute values $(\mathrm{g})$ or relative to body weight, the mean liver wet weight was higher $(\mathrm{p}<$ 0.001 ) in STZ rats than in control animals, whilst no signifi-

Table 1. Wet Weight of Pancreas, Kidneys and Liver

\begin{tabular}{|c|c|c|c|}
\hline Rats & NF & IF & CR \\
\hline \multicolumn{4}{|c|}{ Pancreas } \\
\hline \multirow[t]{2}{*}{ Control } & $0.68 \pm 0.11(4)^{\mathrm{a}}$ & $0.58 \pm 0.05$ & $0.83 \pm 0.09$ \\
\hline & {$[0.27 \pm 0.05]^{\mathrm{b}}$} & {$[0.26 \pm 0.03]$} & {$[0.33 \pm 0.03]$} \\
\hline \multirow[t]{2}{*}{ STZ } & $0.85 \pm 0.01$ & $0.74 \pm 0.01$ & $0.87 \pm 0.04$ \\
\hline & {$[0.44 \pm 0.02]$} & {$[0.37 \pm 0.02]$} & {$[0.44 \pm 0.02]$} \\
\hline \multicolumn{4}{|c|}{$\underline{\text { Right kidney }}$} \\
\hline \multirow[t]{2}{*}{ Control } & $0.98 \pm 0.07(5)$ & $0.90 \pm 0.03$ & $0.89 \pm 0.03(6)$ \\
\hline & {$[0.38 \pm 0.02]$} & {$[0.40 \pm 0.02]$} & {$[0.36 \pm 0.01]$} \\
\hline \multirow[t]{2}{*}{ STZ } & $1.44 \pm 0.16(6)$ & $1.16 \pm 0.03(6)$ & $1.19 \pm 0.08(6)$ \\
\hline & {$[0.75 \pm 0.03]$} & {$[0.58 \pm 0.02]$} & {$[0.58 \pm 0.03]$} \\
\hline \multicolumn{4}{|c|}{ Left kidney } \\
\hline \multirow[t]{2}{*}{ Control } & $0.95 \pm 0.06(5)$ & $0.89 \pm 0.03$ & $0.87 \pm 0.02(6)$ \\
\hline & {$[0.38 \pm 0.02]$} & {$[0.39 \pm 0.01]$} & {$[0.35 \pm 0.01]$} \\
\hline \multirow[t]{2}{*}{ STZ } & $1.34 \pm 0.12$ & $1.15 \pm 0.03(6)$ & $1.17 \pm 0.06(6)$ \\
\hline & {$[0.70 \pm 0.07]$} & {$[0.58 \pm 0.01]$} & {$[0.58 \pm 0.03]$} \\
\hline \multicolumn{4}{|c|}{$\underline{\text { Liver }}$} \\
\hline \multirow[t]{2}{*}{ Control } & $7.60 \pm 0.08(5)$ & $7.22 \pm 0.56(5)$ & $7.42 \pm 0.28(6)$ \\
\hline & {$[3.01 \pm 0.10]$} & {$[3.16 \pm 0.25]$} & {$[3.04 \pm 0.10]$} \\
\hline \multirow[t]{2}{*}{ STZ } & $10.11 \pm 0.28$ & $9.23 \pm 0.32(6)$ & $9.49 \pm 0.49(6)$ \\
\hline & {$[5.26 \pm 0.17]$} & {$[4.62 \pm 0.16]$} & {$[4.67 \pm 0.16]$} \\
\hline
\end{tabular}


cant difference was observed between the NF, IF and CR rats, whether in control or STZ animals.

Likewise, whether expressed in absolute terms (g) or relative to body weight, the mean kidney wet weight was higher $(\mathrm{p}<0.001)$ in STZ rats than in control animals and, in the former STZ rats, higher in the NF animals than in the IF and CR animals ( $\mathrm{p}<0.005$ or less).

\section{Liver Histology and Glycogen Content}

The liver slides prepared from STZ rats apparently displayed more intense PAS staining than those obtained from control animals, suggesting glycogen accumulation in the former rats (Fig. 1). The liver glycogen content (expressed as $\mu \mathrm{g}$ per $\mathrm{mg}$ liver wet weight) was indeed higher in the STZ rats $(13.28 \pm 2.08 ; \mathrm{n}=17)$ than in the control animals $(7.30 \pm$ $2.08 ; \mathrm{n}=17)$, the mean results recorded in the latter control rats representing no more than $47.8 \pm 14.3 \%(n=16 ; \mathrm{p}<$ 0.02 ) of the mean corresponding values found in the STZ rats $(100.0 \pm 13.9 \% ; n=17)$ exposed to the same feeding schedule (NF, IF or CR).

\section{Kidney Histology and PCNA Index}

As illustrated in (Fig. 2), the kidney of NF STZ rats revealed, by optical histology of slices stained with Schiff periodic acid, the presence of Armanni-Ebstein cells with posi- tive grains in the cytoplasmic periphery mainly located in proximal tubules. In the vicinity of these cells, the presence of dilated and atrophic tubules was also noticed (Fig. 2, panel A2). Such findings were less pronounced in the other diabetic animals, especially in the IF STZ rats.

Pooling together all available data, the PCNA index was, as expected, significantly higher $(\mathrm{p}<0.001)$ in the STZ rats $\left(192.3 \pm 13.610^{-4} ; \mathrm{n}=106\right)$ than in the control animals (134.3 $\left.\pm 9.310^{-4} ; \mathrm{n}=91\right)$ (Fig. 3). It was unexpectedly higher in three IF control animals than in either four NF control rats $p<0.02)$ or three CR control rats $(p<0.001)$. It was lower $(\mathrm{p}<0.04)$ in the IF and CR STZ rats $\left(171.7 \pm 12.310^{-}\right.$ $\left.{ }^{4} ; \mathrm{n}=70\right)$ than in the NF STZ rats $\left(232.3 \pm 31.610^{-4} ; \mathrm{n}=36\right)$.

\section{Plasma Creatinine and Urea Concentration}

The plasma concentration of creatinine did not differ significantly ( $p>0.19$ or more) in the 3 groups of control rats (Table 2), with an overall mean value of $1.71 \pm 0.16 \mathrm{mg} / \mathrm{dl}$ (n $=12)$. It was about twice higher $(\mathrm{p}<0.003)$ in the NF STZ rats $(3.43 \pm 0.63 \mathrm{mg} / \mathrm{dl} ; \mathrm{n}=4)$. The measurements collected in the IF and CR STZ rats, when expressed relative to the mean value found in control animals exposed to the same feeding schedule (IF or CR) averaged $135.5 \pm 15.2 \%(\mathrm{df}=$ $12)$, as distinct $(\mathrm{p}<0.06)$ from $246.4 \pm 71.7 \%(\mathrm{df}=6)$ in the NF animals.
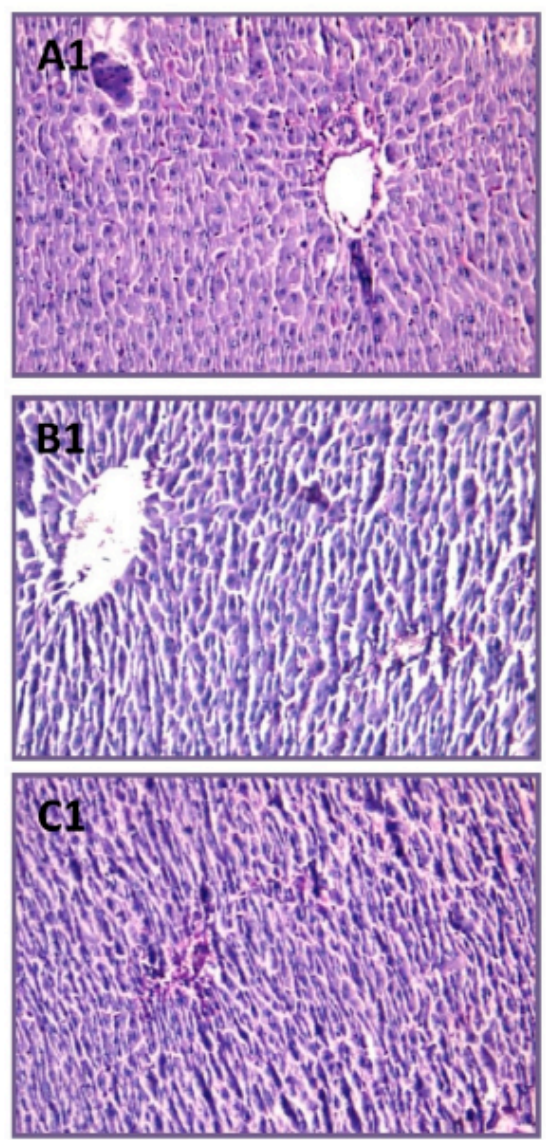
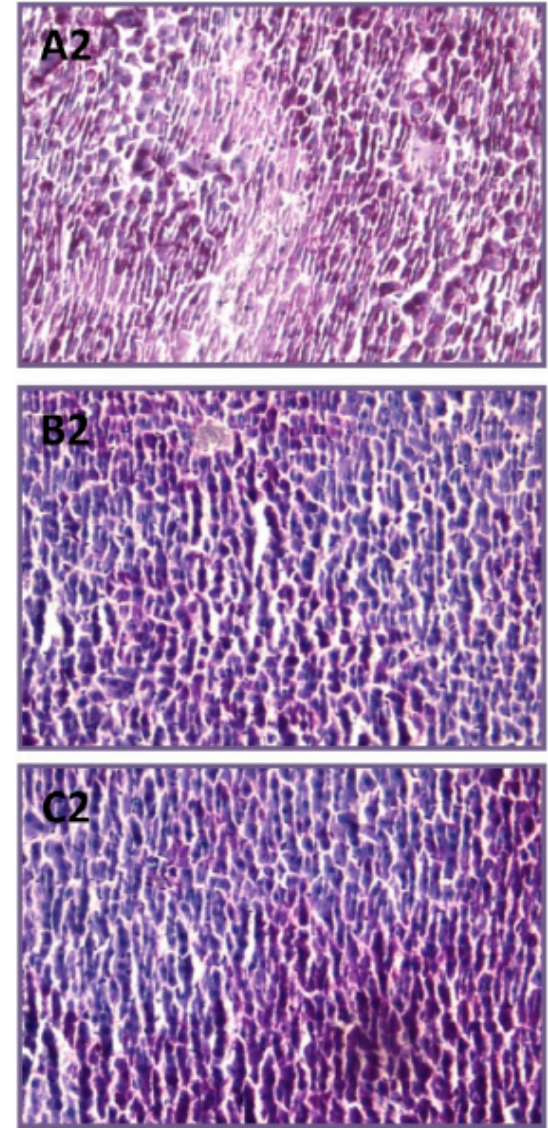

Fig. (1). PAS stained liver histological slides obtained from non-fasting (A), intermittently fasting (B) and calorie-restricted (C) control (1) or STZ (2) rats (magnification x200). 

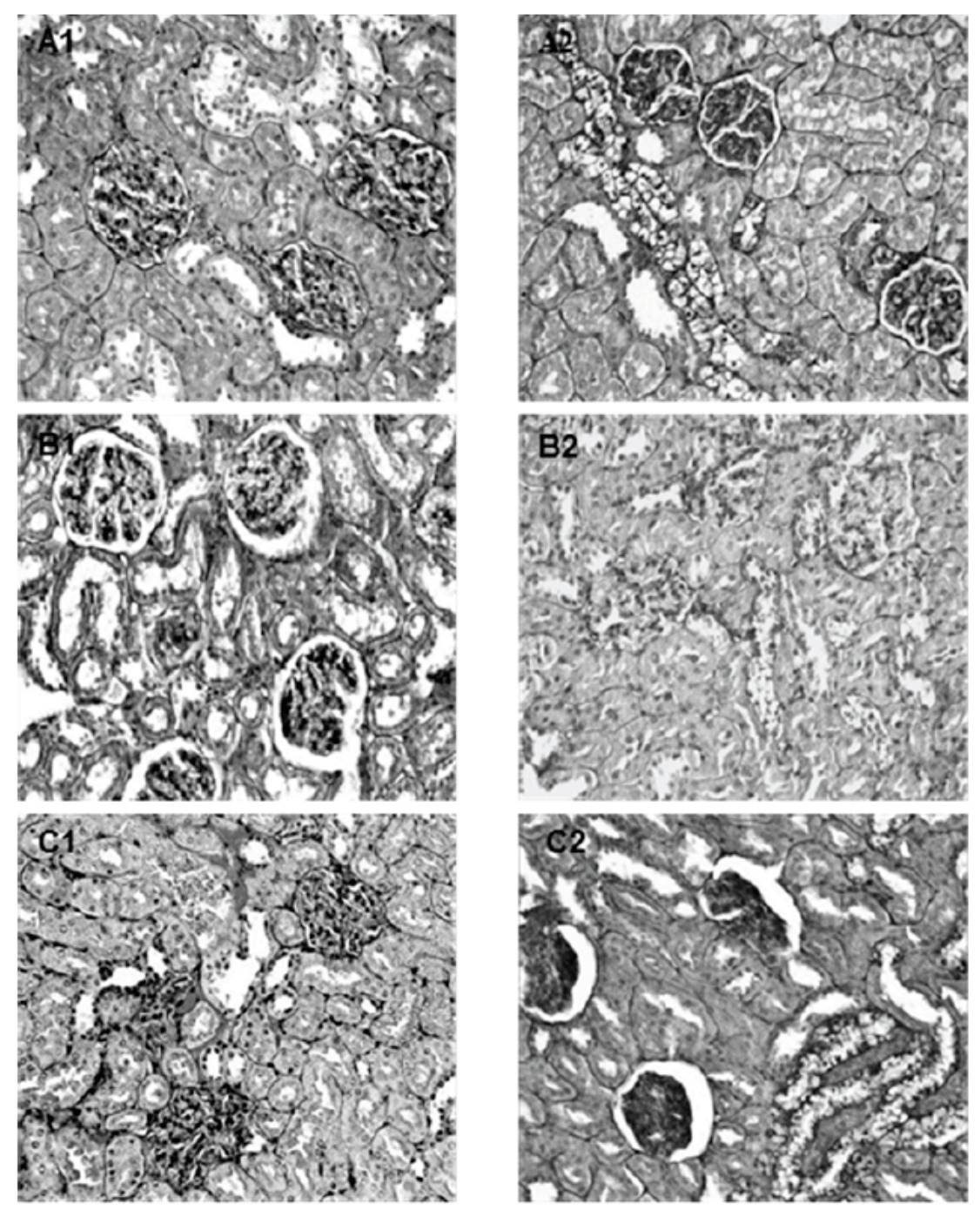

Fig. (2). Schiff periodic acid kidney histological slides obtained from non-fasting (A), intermittently fasting (B) and calorie-restricted (C) control (1) or STZ (2) rats (magnification x 200).
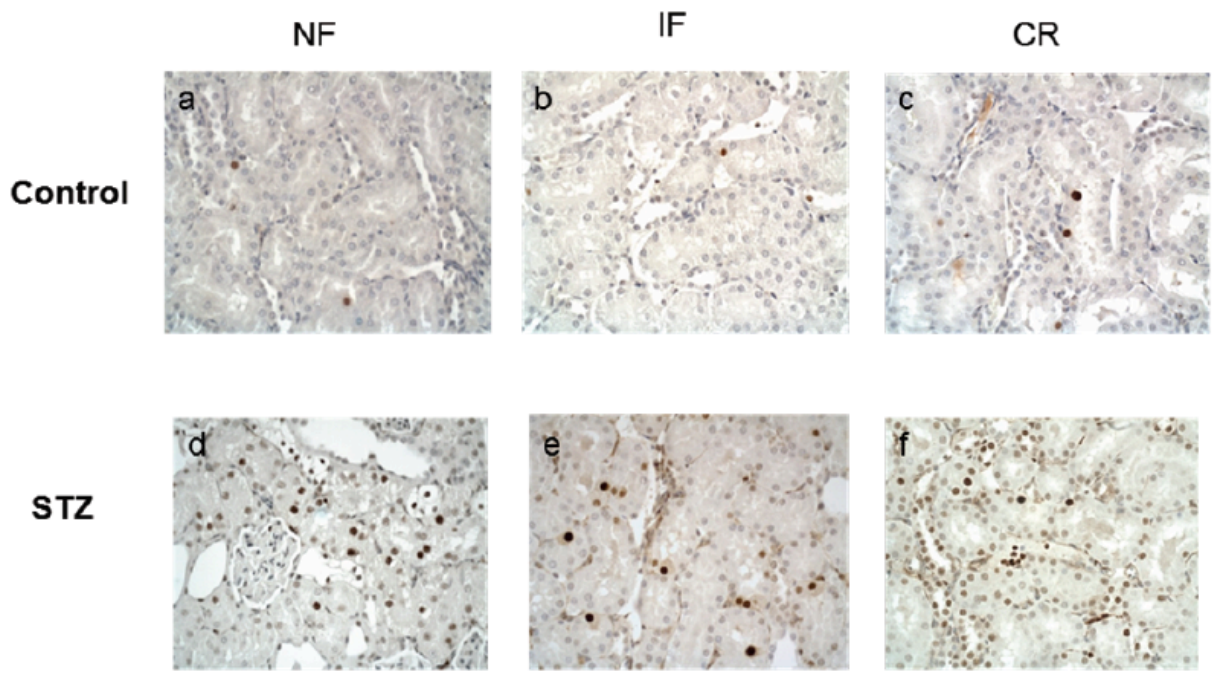

Fig. (3). Immunohistochemical expression of proliferative cellular antigen (PCNA) in the renal cortical sections from rats. PCNA positive cells show dark brown nuclei. In STZ rats (d-f), expression of PCNA was enhanced as compared to control (a-c). Magnification: $x 400$. 
A comparable situation prevailed in the case of the plasma concentration of urea (Table 2). Indeed the latter concentration did not differ significantly ( $p>0.10$ or more) in the 3 groups of control rats, with an overall mean value of $38.8 \pm 5.4 \mathrm{mg} / \mathrm{dl}(\mathrm{n}=12)$. The plasma concentration of urea was about thrice higher $(\mathrm{p}<0.001)$ in the NF STZ rats $(118.3 \pm 30.3 \mathrm{mg} / \mathrm{dl} ; \mathrm{n}=4)$. The measurements collected in the IF and CR STZ rats, when expressed relative to the mean value found in control animals exposed to the same feeding schedule (IF or CR) averaged $163.7 \pm 35.8 \%(\mathrm{df}=12)$, as compared $(\mathrm{p}<0.02)$ to $404.3 \pm 112.0 \%(\mathrm{df}=6)$ in the NF animals.

Even the absolute values for plasma creatinine and urea concentration recorded in the IF and CR STZ rats represented no more than $67.0 \pm 5.1 \%(\mathrm{n}=16 ; \mathrm{p}<0.02)$ of the mean corresponding absolute values found for the same nonproteic nitrogen-containing metabolite in the NF STZ rats $(100.0 \pm 14.6 \% ; \mathrm{n}=8)$.

Table 2. Plasma Creatinine and Urea Concentrations

\begin{tabular}{|c|c|c|}
\hline Rats & Creatinine (mg/dl) & Urea (mg/dl) \\
\hline \hline NF control & $1.39 \pm 0.31(4)$ & $29.3 \pm 3.1(4)$ \\
\hline NF STZ & $3.43 \pm 0.63(4)$ & $118.3 \pm 30.3(4)$ \\
\hline IF control & $1.78 \pm 0.24(4)$ & $42.0 \pm 5.8(4)$ \\
\hline IF STZ & $2.48 \pm 0.26(4)$ & $73.0 \pm 7.6(4)$ \\
\hline CR control & $1.98 \pm 0.24(4)$ & $45.3 \pm 1.5(4)$ \\
\hline CR STZ & $2.60 \pm 0.24(4)$ & $70.0 \pm 20.2(4)$ \\
\hline
\end{tabular}

\section{DISCUSSION}

The present study affords several new pieces of information concerning the effects of intermittent fasting or calorie restriction in the diabetic syndrome of STZ-induced diabetic rats.

First, in the STZ rats, which displayed higher pancreatic, hepatic and renal weight, expressed relative to body weight, the values recorded for the pancreas and kidney weight were lower either in IF than in NF or CR rats (pancreas) or in IF and $\mathrm{CR}$ than NF rats (kidney).

Second, as expected from recent findings recorded in either diabetic rats [5] or type 1 diabetic subjects [6,7], the glycogen content of the liver was higher in the STZ rats than in the control animals. Such a glycogen accumulation, coinciding with severe hyperglycemia, was recently referred to as a glycogenic hepatopathy [6]. The proposed link between hyperglycemia and liver glycogen accumulation is supported by the finding, in this study, of a significant positive correlation $(\mathrm{r}=+0.4039 ; \mathrm{n}=33 ; \mathrm{p}<0.03)$ between the individual values for plasma glucose concentrations at sacrifice and liver total carbohydrate content. The incipient process of necrosis found in the NF STZ rats may conceivably reflect the oxidative stress attributable to hyperglycemia in these diabetic animals.
Hyperglycemia may lead to nephropathy. The first repercussion of chronic hyperglycemia consists in a rapid attack of the structural and functional integrity of kidney glomerular mesangium cells, which normally insure the efficiency of glomerular filtration [8]. Thus, in the first step preceding glomerulosclerosis, these mesangial cells undergo transient moderate hyperplasia, followed by progressive hypertrophy, as observed by Young et al. [9] in the STZ diabetic model. Likewise, in (Fig. 3), the PCNA positive cells are located mainly in the tubule-intersticial space, in fair agreement with a prior study [10]. Renal hypertrophy was also observed shortly after the injection of STZ by Chen et al. [11]. According to Kobayashi and Venkatachalam [12], a 2- to 3-fold increase in plasma creatinine concentration prevails in diabetic rats. In the present study, such an increase was accompanied by an increase in the plasma urea concentrations. These findings extend to functional variables the morphological alterations found in the STZ rats. The presence of Armanni-Ebstein cells in renal slides represents a typical phenotypic feature of the diabetic kidney [13]. In the present study, both the histological and functional perturbations found in NF STZ rats were, as a rule, less pronounced in IF and CR STZ rats, in fair agreement with a prior observation [14].

The hierarchy between the mean values for the kidney PCNA index in the three groups of STZ rats considered in the present study is also compatible with a beneficial effect of intermittent fasting and/or calorie restriction on renal function. In this respect, a significant negative correlation $(\mathrm{r}$ $=-0.8497 ; \mathrm{n}=6 ; \mathrm{p}<0.04)$ was observed between the mean values for the kidney PCNA index (Table 3) and the corresponding mean absolute values for the total $\beta$-cell mass (Table $\mathbf{5}$ in reference [1]) in the six groups of rats under consideration in this study.

Table 3. Kidney Histology and PCNA Index

\begin{tabular}{|c|c|c|c|}
\hline Rats & NF & IF & CR \\
\hline \hline Control & $123.2 \pm 13.1(26)^{\mathrm{a}}$ & $186.9 \pm 21.6(28)$ & $102.3 \pm 10.1(36)$ \\
\hline STZ & $232.3 \pm 31.6(36)$ & $178.6 \pm 16.6(32)$ & $165.9 \pm 18.0(38)$ \\
\hline
\end{tabular}

${ }^{\text {a Expressed as } 10^{-4}}$

In conclusion, therefore, the present findings reinforce the view that intermittent fasting, in such animal models of diabetes mellitus as sand rats [15-17] or STZ rats [1], may exert a favourable effect in terms of glucose homeostasis and the metabolic and functional undesirable consequences of its perturbation.

\section{CONFLICT OF INTEREST}

The author(s) confirm that this article content has no conflicts of interest.

\section{ACKNOWLEDGEMENT}

Declared none. 


\section{REFERENCES}

[1] Belkacemi L, Selselet-Attou G, Hupkens E, et al. Intermittent fasting modulation of the diabetic syndrome in streptozotocininjected rats. Int J Endocrinol 2012; 2012: 962012.

[2] Lowry OH, Passonneau JV. A flexible system of enzymatic analysis. New York, NY, USA: Academic Press, 1972; p. 191.

[3] Pardue HL, Bacon BL, Groeger-Nevius M, Skoug JW. Kinetic study of the Jaffe reaction for quantifying creatinine in serum: 1 . Alkalinity controlled with $\mathrm{NaOH}$. Clin Chem 1987; 33: 278-85.

[4] Talke H, Schubert GE. Enzymatic urea determination in the blood and serum in the Warburg optical test. Klin Wochenschr 1965; 43: 174-5.

[5] Akinola B, Dosumu OO, Akinola OS, Zatta L, Dini L, CaxtonMartins EA. Azadirachta indica leaf extract ameliorates hyperglycemia and hepatic glycogenosis in streptozotocin-induced diabetic wistar rats. Int J Phytomed 2010; 2: 320-31.

[6] Torbenson M, Chen Y, Brunt E, et al. Glycogenic hepatopathy: An underrecognized hepatic complication of diabetes mellitus. Am J Surg Pathol 2006; 30: 508-13

[7] Van den Brand M, Elving LD, Drenth JPH, van Krieken JHJM. Glycogenic hepatopathy: a rare cause of elevated serum transaminases in diabetes mellitus. Neth J Med 2006; 67: 394-6.

[8] Geoffroy K, Troncy L, Wiernsperger N, Lagarde M, El Bawab S. Glomerular proliferation during early stages of diabetic nephropathy is associated with local increase of sphingosine-1-phosphate levels. FEBS Lett 2005; 579: 1249-54.

[9] Young BA, Johnson RJ, Alpers CE, et al. Cellular events in the evolution of experimental diabetic nephropathy. Kidney Int 1995; 47: $935-44$.
[10] Gross ML, Ritz E, Schoof A, et al. Comparison of renal morphology in the Streptozotocin and the SHR/N-cp models of diabetes. Lab Invest 2004; 84: 452-64.

[11] Chen H, Brahmbhatt S, Gupta A, Sharma AC. Duration of streptozotocin-induced diabetes differentially affects p38-mitogenactivated protein kinase (MAPK) phosphorylation in renal and vascular dysfunction. Cardiovasc Diabetol 2005; 4: 13.

[12] Kobayashi S, Venkatachalam MA. Differential effects of calorie restriction on glomeruli and tubules of the remnant kidney. Kidney Int 1992; 42: 710-7.

[13] Watanabe Y, Hotta N. Tubulointerstitial injury in diabetes mellitus (including Armanni-Ebstein lesion). Ryoikibetsu Shokogun Shirizu 1997; 17: 225-8.

[14] Tikoo K, Tripathi DN, Kabra DG, Sharma V, Gaikwad AB. Intermittent fasting prevents the progression of type I diabetic nephropathy in rats and changes the expression of Sir2 and p53. FEBS Lett 2007; 581: 1070-8.

[15] Belkacemi L, Selselet-Attou G, Sener A, Malaisse WJ. Intermittent fasting modulation of the diabetic syndrome in sand rats. I. Background information and experimental design. Metab Funct Res Diabetes 2009; 2: 5-8.

[16] Belkacemi L, Selselet-Attou G, Louchami K, Sener A, Malaisse WJ. Intermittent fasting modulation of the diabetic syndrome in sand rats. II. In vivo investigations. Int J Mol Med 2010; 26: 75965 .

[17] Belkacemi L, Selselet-Attou G, Bulur N, et al. Intermittent fasting modulation of the diabetic syndrome in sand rats. III. Post-mortem investigations. Int J Mol Med 2011; 27: 95-102.

\section{Received: March 29, 2013 \\ (C) Belkacemi et al.; Licensee Bentham Open.}

Revised: June 18, 2013

Accepted: June 20, 2013

This is an open access article licensed under the terms of the Creative Commons Attribution Non-Commercial License (http://creativecommons.org/licenses/by-nc/3.0/) which permits unrestricted, non-commercial use, distribution and reproduction in any medium, provided the work is properly cited. 